\title{
Exploration of Ornamental Mould and Implication of Chinese Folk Gourd Art
}

\author{
Xuefang $\mathrm{He}^{1, \mathrm{a}}$, Bing Liu ${ }^{1, \mathrm{~b}, \text { * }}$ \\ ${ }^{1}$ Academy of Fine Arts, Northeast Normal University, Changchun130024, China \\ ah567809@126.com, bice8515@163.com \\ ${ }^{*}$ Corresponding author
}

Keywords: Gourd Art, Chinese Folk art, Intangible Heritage, Ornamental Mould, Implication.

\begin{abstract}
Gourd art is the ancient Chinese life memory and living cultural gene, it has a unique style and exquisite artistic connotation, from the point of view of inheritance, on the basis of carding the development of the gourd art; this paper makes a deep study of its creation thought, aesthetic characteristics, cultural connotation and folk custom meaning. Research shows: gourd art has a strong taste of life and aesthetic meaning, shape smart and elegant, the combination of auspicious patterns and gourd art, fully embodies the people's good wishes, and it contains profound folk spirit and Taoist philosophy.
\end{abstract}

\section{中国传统匏器艺术造型溯源及其民俗意蕴探究}

\author{
何雪芳 $1, a$, 刘冰 $1, \mathrm{~b},{ }^{*}$ \\ 1东北师范大学美术学院, 长春, 吉林, 中国 \\ an567809@126.com, bice8515@163.com \\ 通讯作者
}

关键词: 鴒器; 中国民俗艺术; 非遗传承; 形式特征; 象征意蕴

中文摘要. 塔器艺术是中华民族古老的生命记忆和活态的文化基因, 拥有独树一帜的造型风 格和精雕细环的技艺内涵。祥和盛世, 对文化起着涵养、催化的作用, 歇器收藏把玩的繁盛, 促进了歇器艺术的研究, 本文以继承之视角, 在梳理歇器艺术发展脉络的基础上, 对其造物 思想、审美特征、文化内涵、民俗意蕴进行了深入探究, 研究表明匏器艺术具有浓厚的生活 情趣和审美意味, 造型灵动又不失典雅, 吉祥纹样与欨器的结合充分体现了人们对吉祥幸福 和子嗣繁荣的美好愿望, 蕴含着深遂的民俗精神和道家哲学思想。

\section{1. 引言}

匏（音 páo）器, 又名“葫芦器”或“蒲器”, 是一种以天然葫芦为素材, 将自然美和民族 文化融为一体的传统艺术。匏器, 起于明兴于清, 康熙年间发展至顶峰, 颇受皇家重视, 其 造物思想与审美文化容纳阴阳五行、八卦、洛书九宫、堪與七政、天文九星等哲学理论, 博 大精深, 其装饰纹样融合民俗学、人类学、社会学等文化寓意, 具有鲜明的民族文化特征[1-3]。 匏器文化是一种特殊的“玩儿文化”, 清朝时, 塔器进入皇宫, 成为皇家御用的工艺品, 在宫 廷的督造下, 当时的歇器工艺已臻精至, 种类纷繁, 地位可胜金玉。歇器具有特殊的纹理和 颜色, 老熟的匏器色黄如金, 时间越久, 颜色越重, 包浆后紫润光洁, 悦目娱心, 匏器除供 
御前赏玩外, 也寄予了博雅君子朗风雯月的清疏之风, 匏器通体一色, 或满饰雕刻, 或简洁 风致, 装饰线条酒脱又不失繁华之美, 遂成清代以来宫廷乃至文人雅士互赠彼此的吉祥之物, 清康熙帝曾以塔器赠送彼得大帝, 乾隆帝也曾将一枚精美绝伦的葫芦鼻烟壶交给访华的英国 大使马噶尼，转赠与英王乔治三世。

匏器的存世量相对有限, 多存于海内外各大博物艺术馆与少数收藏家手中，北京故宫博 物院保存匏器藏品共590件，2003年，一件清乾隆年间“模印八仙纹”匏瓶在中国嘉德秋拍中以 63.8 万高价落幕，2005年，HK苏富比拍卖清康熙年间“葫芦印团寿纹”菢器，价格38.16万元， 2011年西泠印社的春拍中, 一件清代巧雕菢器以69万元成交, 创下内地塔器拍卖的新纪录。 菢器是集文艺欣赏和把玩收藏于一身的传统手工艺术, 其装饰纹样多源于民族文化与图腾崇 拜, 塔器文化是民族传统文化的重要组成部分, 同时也具有较高的工艺、艺术和文化的收藏 价值, 塔器的收藏与研究不单是对民间艺术的珍视, 更是在找寻那段历史[4-6]。

\section{2. 款器艺术造型溯源}

华夏中原最早将葫芦称为姱瓜（音 hù）、塔和壶，在《诗经》、《论语》中均有提及，《诗

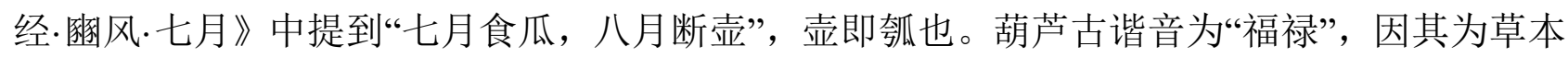
植物，枝茎称为“蔓”，与“万”谐音，“蔓带”与“万代”谐音，古人意“福禄”“万代”便是“福禄寿”， 即三福齐全，故葫芦自古以来被视作吉祥的象征，象征家丁兴旺、代代昌盛。“种葫、制范、 纳范、拆范、结勒扎、火画、押花和刀刻工艺, 得独具一格之匏器”, 塔器原始的造型形态是 在天然的葫芦上套上模具而得的三维立体造型, 并与传统吉祥纹样交相辉映, 类别含实用器 皿和陈设艺术品两类, 囊括罐, 瓶, 盆, 碟, 碗, 笔筒、鼻烟, 笼及乐器等多种样式。

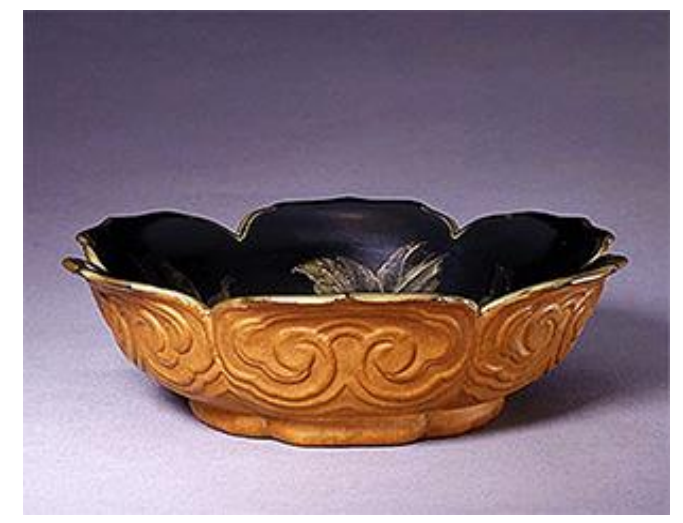

图1. 勾云纹漆里花口盘

规格：高 $5 \mathrm{~cm}$, 口径 $16.8 \mathrm{~cm}$, 足径 $9.2 \mathrm{~cm}$

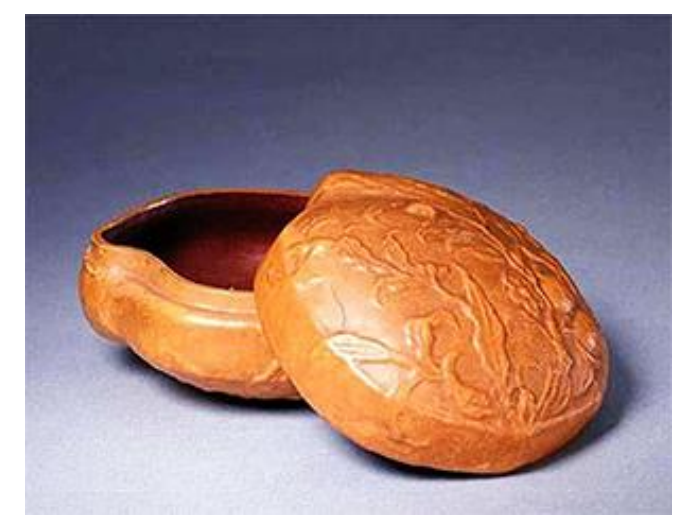

图2. 湤制福寿纹桃式盒

规格：通高 $7.6 \mathrm{~cm}$, 内口最大径 $8.9 \mathrm{~cm}$

范制葫芦上山水风景、历史人物、神话传说等各类气韵充沛的吉祥纹样，精微工巧，充 分体现时代意蕴和审美风尚, 康熙时期制作的范制塔器质朴光素而不施雕饰, 乾隆时期繁复 富丽而庄重, 金漆裸涂或腹有莲纹, 色如蒸栗, 深受收藏者的喜爱。自然仿生是匏器造型主 要的表现形式, 即通过感性的观察, 将自然界中的动植物饶有韵味的形态与塔器相结合, 勾 云纹漆里花口盘（图1），盘为六出葵瓣式，每瓣云纹一朵，迴旋圆婉，盘内壁漆黑地上以金 漆绘折枝牡丹一朵, 运用仿生手法, 造型结合葵花并适度夸张, 是匏器与葵花相互交融的物 化形式, 从视觉上体现匏器的巧而得体、精而合宜, 灿烂夺目; 蚫制福寿纹桃式盒（图2）, 造型恰如剥开的桃实, 盖顶、底面均饰凸起的桃枝、桃叶、桃花、桃实纹, 充分体现了匏器 的使用功能和装饰形式的完美契合; 匏制蒜头瓶 (图3), 瓶肩有斜纹云饰, 腹莲花纹, 瓶身 如花瓣聚拢, 纹饰别致, 色如蒸栗, 芗澈可鉴, 令人爱不释手; 寿山福海纹笔筒（图4), 象 牙钤口，倒印蝙蝠，砑花山石、海水、桃枝，寓祈福之意，纹路清晰饱满。 


\section{1 麭器造型纹样对吉祥幸福的信仰}

匏器艺术离不开哲学审美及象征意蕴的融合, 塔器在设计与制作的过程中, 多以吉祥纹 样为饰, 以此来增强匏器的审美价值。在吉祥纹样与湤器 “融合” 的装饰意义上, 大多数的匏 器装饰采取直 接取其“意”, 通过结合的方式来表达“吉祥”的内容, 匏器与吉祥纹样中“求吉” 的这一点不谋而合, 这也使得吉祥纹样与歇器的结合显得顺理成章, 中国最早的国别史著作 《国语·楚语卷一》中写到“先君庄王为匏居之台, 高不过望国氛”, 其“匏居之台”, 即国家凶 吉的观测台，显然楚人是把匏作为占卜“国氛”的灵物来使用的。

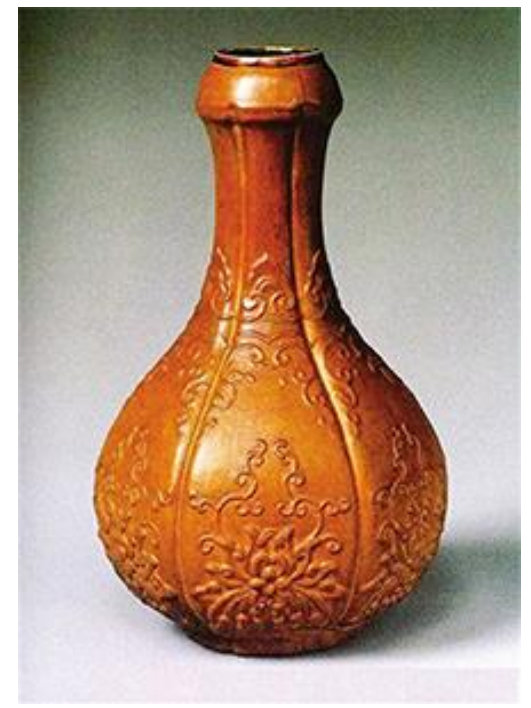

图3. 匏制蒜头瓶

规格：高 $13.8 \mathrm{~cm}$, 口径 $4.1 \mathrm{~cm}$, 足径 $7.2 \mathrm{~cm}$

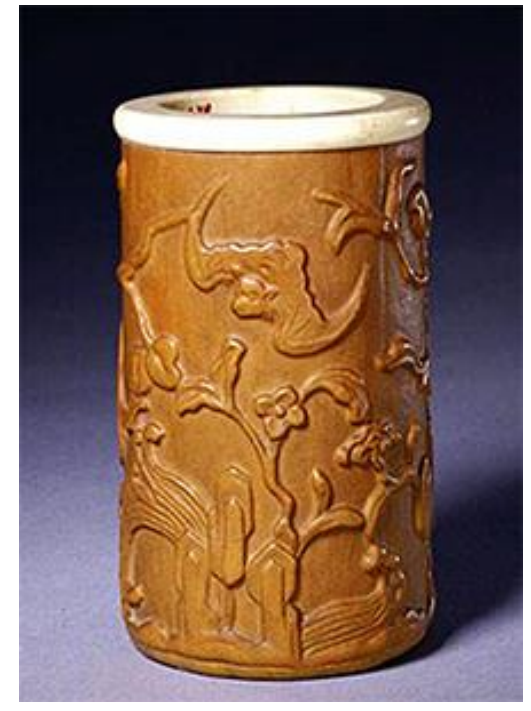

图4. 寿山福海纹笔筒 规格：高 $11.2 \mathrm{~cm}$, 口径 $6.4 \mathrm{~cm}$

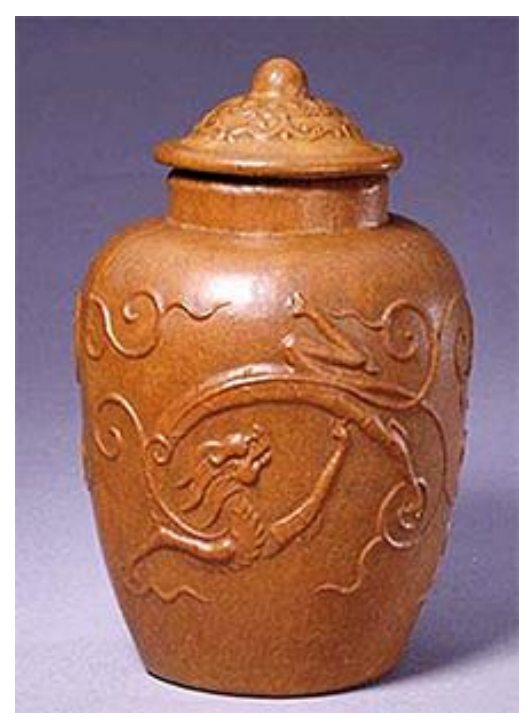

图5. 蕃莲螭纹蓋（音hé）罐 规格: 高 $15.3 \mathrm{~cm}$ 口径 $5.8 \mathrm{~cm}$ 底径 $6.7 \mathrm{~cm}$

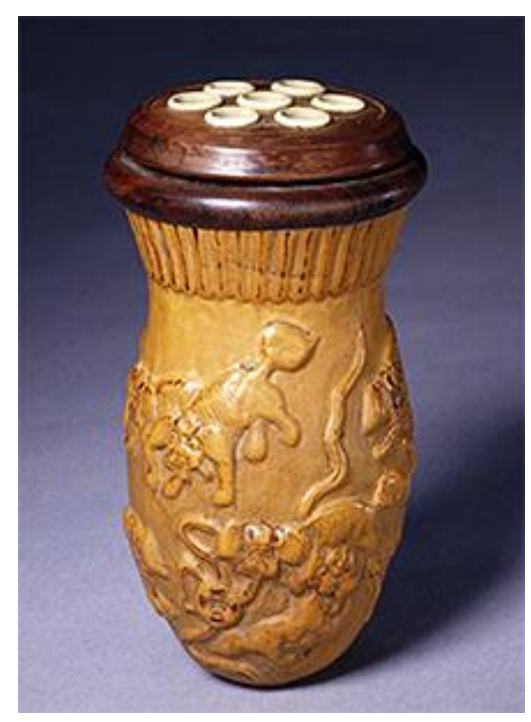

图6. 狮子戏钱纹蝈蝈罐 规格: 通高 $12.1 \mathrm{~cm}$

匏器中的吉祥纹样大体分为四大类: 吉祥动物、吉祥植物、吉祥文字、民间神祇, 蕃莲 螭纹蓋 (图5), 罐附螭纹, 古代因螭祈雨, 螭即龙属, 祈求农耕䖯桑之利, 东汉《说文解字》 一书写道: “螭, 若龙而黄, 北方谓之地蝼, 从虫, 离声, 或无角曰螭”, 螭纹盘缠卷曲与流 云为伴, 颇有威武神秘与灵动之感, 体现出了匏器的趣味与吉祥寓意的精雅追求; 狮子戏钱 纹蝈蝈罐（图6）, 是范制葫芦与狮子纹联姻之结晶, 明代《瀛涯胜览》记载: “狮子形如虎, 
黑黄无斑, 头大口阔, 尾尖毛多, 黑长如缨, 声吼如雷, 伏不敢起, 乃兽中之王也”，故此， 狮子纹常因威严、吉祥进入人们的生活，人们希望通过狮子威猛的气势来彰显权贵、驱邪纳 祥; 勾云团寿字纹盘（图7）和匏制凸花纹盘（图8），匏器与“卷草纹”“芹”相结合，卷草纹 外形呈“S”状, 其取佛物之情态, 得祥云之神气。“与”（音Wan）字符, 在我国新石器时代遗 址中的彩陶上就已呈现, 它象征着阳光、漩涡与太阳, 二者皆呈胎儿在母亲腹中的卷曲状, 这也使得人们认为此类螺旋纹样是生命与万物的重要象征。

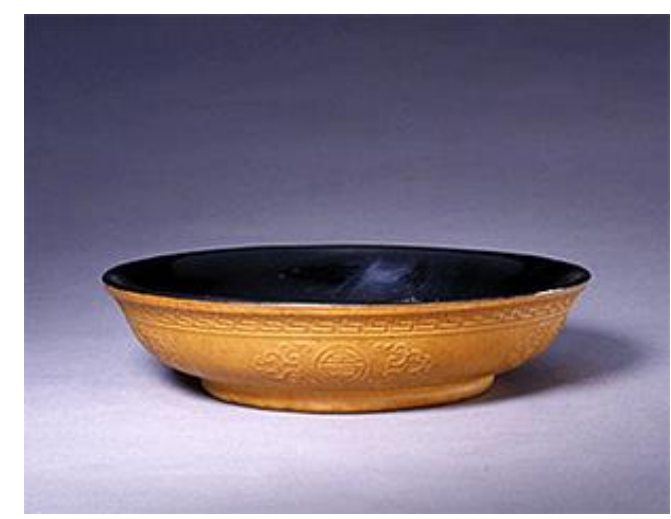

图7. 勾云团寿字纹盘 规格：高 $4.2 \mathrm{~cm}$, 口径 $17.1 \mathrm{~cm}$, 底径 $10.4 \mathrm{~cm}$

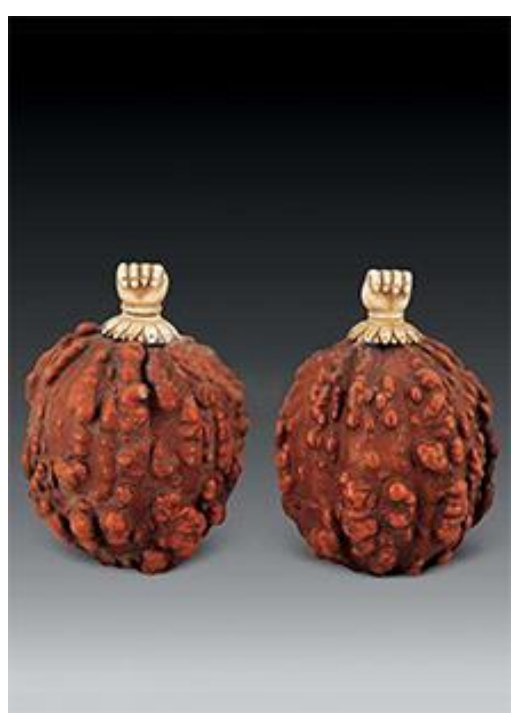

图9. 百子麭器 规格: 不详

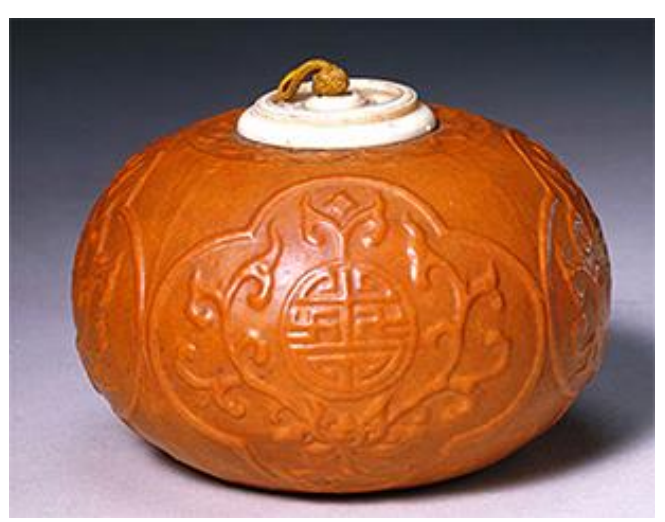

图8．匏制凸花纹盘 规格: 通高 $5.7 \mathrm{~cm}$, 口径 $2.2 \mathrm{~cm}$

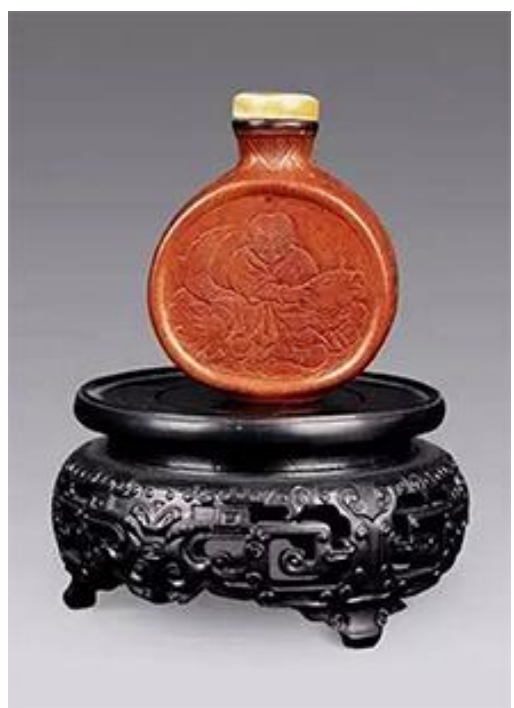

图10. 年年有余匏器鼻烟壶 规格: 不详

\section{2 匏器造型纹样对生殖生命的信仰}

人们对自然力和氏族祖先有着神秘的畏惧和依赖感，因此把子嗣的兴旺寄托在麒麟、鸟、 鱼、石榴、莲、葫芦等动植物上, 生命象征是匏器艺术形而上层面的深层内涵。《诗经.大雅. 锦篇》中有“绵绵瓜瓜, 民之初生”之句, 《闻一多全集・伏羲考》中有: “汉族以歇为伏羲女 如本身...”，在古代神话中，菢被赋与保护生命的意蕴，成为一种神性的信仰，它不仅是人类 繁衍的源泉, 也是万物的繁衍之源, 百子匏器 (图9), 塔器上不均匀的分布着大小不一的小 葫芦, 这个特征突出表现了人们希望通过旺盛的生殖能力来繁衍子嗣, 寄托了人们对氏族兴 盛的美好意愿; 年年有余匏器鼻烟壶 (图10)，刀刻砑花一敗态可掬的娃娃抱着一锦鲤, 鱼 自古以来就是延绵子嗣、生殖繁衍的象征, 人们把鱼奉为了多子多孙的崇拜对象, 鱼纹样与 塔器的结合充分体现人们对这种生殖能力的渴望。

人们把匏作为男女相交，阴阳结合的始祖，《礼记·郊特性》中记载“阴阳合而万物得”,

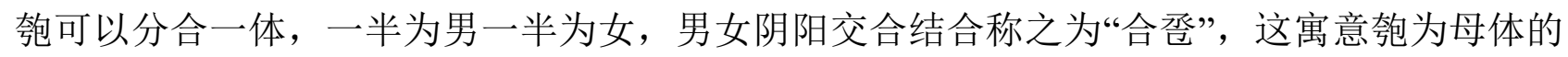


象征, 人类幼年时期尚未认识到男性对生殖的作用, 生殖崇拜主要以女性生殖器为对象, 因 此关于匏的神话实质上是对女性生殖器官崇拜的产物, 匏器作品中的装饰纹样与人们的思想 意识观念相通, 同时也造就了嗒器纹样独特的求子纳福的艺术鬼力, 塔器在古代神话中被赋 予了庇护生命、求福、镇宅、除邪、保佑家庭子孙的神话色彩, 成为了中华民族的一种吉祥 圣物。

\section{3. 鴙器艺术造型的民俗意蕴}

\section{1 麭器的原始宗教信仰与图腾崇拜}

人们对大自然能力的敬畏与疑惑, 产生了种种信仰崇拜, 原始宗教也因此而生, 新石器 的仰韶文化中, 蚫器成为孕育生命的神物, 《礼记・郊特性》中记载“陶匏以象天地性”即阴阳 两性的结合，匏为龙女娲和虎伏羲的共同体，是阴阳合体，是生物的原初母体，是“混沌”最 早的象征物, 它的破裂, 即是一分为二: 阴与阳、雌与雄, 成为繁衍人类的始祖。图腾崇拜 亦称“图腾信仰”, “图腾”可译为“亲属”或“标记”的意思, 我们通常所说的图腾, 就是人们相信 某种动植物为“氏族之祖先, 或与之有血缘关系”, 匏器原始的美术造型文化一个重要的标志 就是“图腾崇拜”，它是匏器美术造型中较早的一种信仰观念。

图腾崇拜是菢器美术造型中的一种信仰观念，如塔器中大量龙纹的运用，“龙纹”是天与 地、阴与阳哲学观念的统一, 是地与阴的象征, 其象征着天阳神祇与地阴神祇图腾的结合体, 是通天通地的图腾动物, 《说文解字》记载: “龙, 鳞虫之长, 能幽能明, 能细能巨, 能短能 长，春分而升天，秋分而潜渊”，人们将对美好的追求寄托在龙身上，通过龙图腾表达对长寿 的渴求。我国众多少数民族聚集的区域依然存在图腾崇拜, 彝族人以塔器为图腾, 他们崇拜 匏器, 并有匏的神话相伴随, 在其他众多的匏器文化遗址中, 匏器上的纹样不单是装饰艺术, 更是图腾崇拜在物质文化上的表现。

\section{2 麭器的道教哲学观}

道教作为中国本土的宗教, 继承了汉民族本源的哲学内涵和生命意义, 为民众的生存诉 求提供世俗化、实用化的宗教信仰依托, 在中国传统文化理念中, 阴和阳为最基本的观念, 起源早于五行、八卦、天干、地支等, 在五经文化的系统里, 是组成《易经》学术系统的中 心思想, 它包罗万象, 囊括千方, 天地、乾坤、日月、宇宙、世界、水火、雌雄、冷暖、生 死、刚柔、动静、吉凶、黑白等, 几乎无所不在, 无所不蓄。葫芦在生长的过程中种子有 365 颗, 自成阴阳, 其外形与道教的八卦图中的阴阳分界线相似, 在道教文化中认为其制成的匏 器可以吸尽天地之间的邪气，老子云：“道恒无名，朴虽小而天下弗敢臣”, “朴”的原形是匏, 为西南少数民族的崇拜物和巫术法具, 被视为“祖灵”或图腾, 具有无限的创生与辟恶功能, 匏在《后汉书》的费长房的故事中被神化, 成为可供神人通天遁地, 菢器已成为道教的法器 和特殊的标志。

在中国人的原始哲学观念中，阴阳观源远流长，根深蒂固，并围绕着“人类从何而来”这 一问题形成，《慈善孝子报恩成道经》中记载: “道为万物父，亦为万物母”，又曰: “道生一， 一生二，二生三，三生万物”人们从男女结合诞生新生命得出“男女精构，万物化生”阴阳结合 而生万物的结论，这也正是道教关于生命起源“阴阳相合生万物，万物永生不息”的观念基本 观点, 这种阴阳五行的发展变化不仅赋予了匏器深刻的传统文化, 同时也给匏器的艺术造型 带来了丰富无穷的样式, 也成就了蚫器艺术独具一格的造型形式。

\section{4. 结语}

传统匏器艺术造型多样, 具有浓厚的生活情趣和审美意味, 造型灵动又不失典雅, 吉祥 纹样与菢器的结合体现了人们对吉祥幸福和子嗣繁荣的美好愿望, 蕴含着丰富的民俗意蕴和 
道家哲学思想。匏器艺术是中华民族的文化积淀, 是中国非物质文化遗产中重要的组成部分, 传统歇器艺术面临着濒临失传的境地, 塔器的传统制作技艺范匏, 勒扎、火画、砑花、刀刻 是生活中不可再生的珍贵资源, 凝结了人民智慧的结晶, 其历史发展脉络、制作工艺、造物 思想与设计文化亟待得到研究与理论总结, 抢救性的保护传承与挖掘这门曾经一度消失的传 统技艺, 对其进行历史维度与专题研究相结合的系统分析, 具有较高的学术价值和重要的历 史意义。匏器艺术面对着新、旧文化链的变化衔接时期, 在国家以及传承人的普及和宣传下, 人们已经开始从人类文化的多样性中思考菢器艺术的可持续发展和传承保护问题, 古为今用, 人们在传承传统制匏工艺的同时，还应取其“意”，传其“神”，把匏器艺术这项传统艺术与多 样的世界文化相结合, 以当代的审美对匏器传统造型和纹样进行提炼和发挥, 只有不断地创 新，改进思维方式，才能确保匏器技艺的存世，创造出具有“传统美”和“装饰美”的新生的、 有民族文化特点的匏器艺术作品。

\section{致谢}

本文为东北师范大学校内青年基金团队项目《明清匏器艺术发展现状的调查与研究》 (17QT008)的阶段性成果之一。

\section{References}

[1] L Fang, The Contemporary Constitution of the Chinese Western Folk-arts, Literature \& Art Studies, vol. 4, pp. 112-122, 2005.

[2] Riri, Jieyuan, Painted and Crafted Gourd: a Traditional Art of China, Cultural exchange between China and foreign countries, 2010, vol. 7, 32-34.

[3] Zhao yiyi, The Decorative Art of Continuous Patterns on the Traditional Chinese Gourd-shaped Articles: the enlightenment for the development of modern gourd painting, Bulletin of Asian Design Culture Society, vol. 9, pp. 95-100, 2015.

[4] LH Xie, SA University, The Inheritance of Innovation: Be Folk Gourd Art, Guizhou Ethnic Studies, vol. 3, pp. 127-130, 2017.

[5] M Barnes, Creative Embellishments for Gourd Art, Schiffer Pub Co, 2014.

[6] By Piccininni, Ann, Storyteller Going out of Her Gourd Artist Immerses Herself in Plant for Area Festival, Daily Herald (Arlington Heights, IL), October 9, 1999. 